\title{
Impact of irbesartan, an angiotensin receptor blocker, on uric acid level and oxidative stress in high-risk hypertension patients
}

\author{
Ryuji Chida $^{1}$, Itaru Hisauchi ${ }^{1}$, Shigeru Toyoda ${ }^{2}$, Migaku Kikuchi ${ }^{2}$, Takaaki Komatsu ${ }^{1}$, Yuichi Hori ${ }^{1}$, \\ Shiro Nakahara ${ }^{1}$, Yoshihiko Sakai ${ }^{1}$, Teruo Inoue ${ }^{2}$ and Isao Taguchi ${ }^{1}$
}

Hyperuricemia is a known cardiovascular risk factor. The angiotensin II receptor blocker (ARB) losartan is known to decrease serum uric acid (UA) level. A recent in vitro study demonstrated a strong interaction between irbesartan and UA transporters that exceeded that of losartan. The purpose of the present study was to evaluate the hypouricemic effect of irbesartan in a clinical setting. A total of $\mathbf{4 0}$ high-risk hypertensive outpatients with coronary artery disease, cerebrovascular disease and/or diabetes complications who were taking ARBs other than irbesartan and losartan were enrolled in this study. After a 4-week control period, the patients' prescribed ARBs were exchanged for an equivalent dose of irbesartan. We assessed blood pressure, heart rate, serum UA level, parameters of lipid and glucose metabolism, cardiac and renal function and inflammatory and oxidative stress markers in blood samples taken immediately before the initiation of irbesartan treatment and again after 12 weeks of treatment. All 40 recruited patients were followed ( 31 men and 9 women, mean age: 68 years) without any dropouts. During the 12 weeks of irbesartan treatment, no significant changes in blood pressure, heart rate, parameters of lipid or glucose metabolism or other biomarkers of cardiac function, renal function, or inflammation were observed. However, UA level $(5.9 \pm 1.6$ to $\left.5.5 \pm 1.6 \mathrm{mg} \mathrm{ml}^{-1}, P=0.028\right)$ and the oxidative stress marker derivative reactive oxygen metabolites (dROMs) $(354 \pm 83$ to $310 \pm 65$ U.CARR, $P<0.001$ ) were significantly lower at 12 weeks of treatment compared with before treatment. These results suggest that irbesartan has beneficial effects on hyperuricemia and oxidative stress.

Hypertension Research (2015) 38, 765-769; doi:10.1038/hr.2015.82; published online 16 July 2015

Keywords: angiotensin receptor blocker; irbesartan; oxidative stress; uric acid

\section{INTRODUCTION}

Hyperuricemia is recognized as a risk factor for cardiovascular diseases, such as hypertension, ${ }^{1-4}$ coronary artery disease and heart failure $^{5,6}$ and type 2 diabetes. $^{7}$ Recent data also indicate that serum uric acid (UA) is a risk marker for progression of chronic kidney disease. $^{8-10}$ The angiotensin II receptor blocker (ARB) losartan has been shown to increase urinary UA excretion and, consequently, to decrease serum UA level. ${ }^{11,12}$ However, other ARBs, such as candesartan and valsartan, do not lower serum UA level. ${ }^{13,14}$ A recent in vitro experiment found a strong interaction between irbesartan and UA transporters that exceeded that of losartan. ${ }^{15}$ In addition, a clinical report showed that irbesartan tended to decrease serum UA level in hypertensive patients with hyperuricemia. ${ }^{16}$ However, very few reports have studied the hypouricemic effect of irbesartan.

We recently reported that irbesartan improved lipid metabolism and oxidative stress in high-risk hypertension patients. ${ }^{17}$ The aim of this study was to determine whether irbesartan also lowers serum UA level in high-risk hypertension patients in a routine clinical setting.

\section{METHODS}

Study design

We recruited 40 outpatients with high-risk hypertension complicated by coronary artery disease, cerebrovascular disease or diabetes. All patients had been taking ARBs other than irbesartan and losartan for $>3$ months and had stable blood pressure. We provided an additional 4-week control period to select patients with well-controlled blood pressure, systolic blood pressure $<135 \mathrm{~mm} \mathrm{Hg}$ and diastolic blood pressure $<85 \mathrm{~mm} \mathrm{Hg}$. After this period, all patients were switched to irbesartan at a dose equivalent to that of their former ARB. We assessed blood pressure and heart rate and collected blood for measurement of serum UA, lipid and glucose metabolism parameters, cardiac and renal function parameters and inflammatory and oxidative stress markers at two time points: immediately before and 12 weeks after initiation of irbesartan treatment. During the 12-week treatment period, irbesartan doses were not changed. At each blood sampling, fasting venous blood was taken from an antecubital vein and was first used for routine blood tests. The remaining blood was immediately centrifuged at $1500 \times g$ for $15 \mathrm{~min}$ at room temperature and was then used for measurement of specific biomarkers. The serum was frozen and stored at $-80^{\circ} \mathrm{C}$ until analysis. The study protocol was

${ }^{1}$ Department of Cardiology, Dokkyo Medical University Koshigaya Hospital, Saitama, Japan and ²Department of Cardiovascular Medicine, Dokkyo Medical University, Tochigi, Japan

Correspondence: Professor I Taguchi, Department of Cardiology, Dokkyo Medical University Koshigaya Hospital, 2-1-50, Minami-Koshigaya, Koshigaya, Saitama 343-8555, Japan. E-mail: taguchi@dokkyomed.ac.jp

Received 4 March 2015; revised 13 April 2015; accepted 1 May 2015; published online 16 July 2015 
approved by the local medical ethics committee, and informed consent was obtained from all patients.

\section{Measurements}

Serum UA level was measured by the uricase peroxidase method. The following lipid and glucose metabolism parameters were measured: levels of serum total cholesterol, triglyceride, high-density lipoprotein (HDL) cholesterol, fasting blood glucose and glycohemoglobin $(\mathrm{Hb}) \mathrm{Alc}$. Total cholesterol and triglyceride levels were determined using enzymatic methods. HDL cholesterol was measured by the precipitation method. Fasting blood glucose was measured by the glucose oxidase method. HbAlc was measured by high-performance liquid chromatography and was expressed according to the National Glycohemoglobin Standardization Program. Low-density lipoprotein (LDL) cholesterol was calculated using the Friedewald formula: LDL cholesterol $\left(\mathrm{mg} \mathrm{dl}^{-1}\right)=$ total cholesterol-HDL cholesterol - (triglycerides/5). For patients with triglyceride levels exceeding $400 \mathrm{mg} \mathrm{dl}^{-1}$, LDL cholesterol was not calculated. N-terminal pro-brain natriuretic peptide (NT-proBNP) was measured using a Roche Diagnostic NT-proBNP electrochemiluminescence immunoassay kit and a Elecsys 2010 analyzer (Roche Diagnostics, Mannheim, Germany) according to the manufacturer's instructions. ${ }^{18}$ Serum creatinine was measured using an enzymatic method, and estimated glomerular filtration rate (eGFR) was calculated using the formula of the Japanese Society of Nephrology CKD Practice Guide: eGFR $\left(\mathrm{ml} \mathrm{min}^{-1}\right.$ per $\left.1.73 \mathrm{~m}^{2}\right)=194 \times($ serum creatinine $\left.\left(\mathrm{mg} / \mathrm{dl}^{-1}\right)\right)^{-1.094} \times(\text { age }(\text { years }))^{-0.287}$. For female patients, the product of this equation was multiplied by a correction factor of $0.739 .{ }^{19}$ High-sensitivity C-reactive protein (hsCRP) level was measured using particle-enhanced technology on a Behring BN II nephelometer (Dade Behring, Newark, DE, USA) with monoclonal anti-CRP antibodies and a calibrator that was traceable to the World Health Organization Reference Material. ${ }^{20}$

Oxidative stress is defined as an imbalance between the production of reactive oxygen metabolites (ROMs) (that is, metabolites of reactive oxygen species) and the removal of reactive oxygen species by a variety of endogenous and exogenous antioxidants. In this study, we assessed oxidative stress via a simple method for the quantification of ROMs, the dROM test, that we had introduced previously. ${ }^{17}$ The dROM test is a photometric method based on the radical reaction of Fenton. The test measures hydroperoxides that are strongly correlated with the amount of ROMs and free radicals. ${ }^{21-23}$

\section{Data analysis}

Values are expressed as the mean \pm s.d. Changes in values were assessed by paired $t$-test. A $P$-value of $<0.05$ was considered statistically significant.

\section{Table 1 Baseline characteristics in 40 patients}

\begin{tabular}{lr}
\hline Age, years & $68 \pm 24$ \\
Males, $n(\%)$ & $31(78)$ \\
Ischemic heart disease, $n(\%)$ & $32(80)$ \\
Cerebrovascular disease, $n(\%)$ & $2(5)$ \\
Diabetes, $n(\%)$ & $18(45)$ \\
& \\
Baseline ARBs & \\
Candesartan, $n(\%)$ & $10(25)$ \\
Valsartan, $n(\%)$ & $12(30)$ \\
Olmesartan, $n(\%)$ & $6(15)$ \\
Telmisartan, $n(\%)$ & $12(30)$ \\
& \\
Combined drugs & \\
Ca blockers, $n(\%)$ & $22(55)$ \\
$\beta$-Blockers, $n(\%)$ & $5(13)$ \\
$\alpha$-Blockers, $n(\%)$ & $6(15)$ \\
Thiazide, $n(\%)$ & $4(10)$ \\
Antidiabetic drugs, $n(\%)$ & $14(35)$ \\
Statins, $n(\%)$ & $35(88)$ \\
\hline Abbreviation: ARB, angiotensin receptor blocker. &
\end{tabular}

Abbreviation: ARB, angiotensin receptor blocker.

\section{RESULTS}

All 40 recruited patients completed follow-up (31 men and 9 women, mean age: 68 years). The previously prescribed ARBs included candesartan in 10 subjects $(25 \%)$, valsartan in 12 subjects $(30 \%)$, olmesartan in 6 subjects (15\%) and telmisartan in 12 subjects $(30 \%)$. The antihypertensive drugs given in combination with the ARBs were calcium channel blockers in 22 subjects (55\%), $\beta$-blockers in 5 subjects $(13 \%), \alpha$-blockers in 6 subjects $(15 \%)$ and thiazide diuretics in 4 subjects (10\%). Antidiabetic drugs and statins were being taken by $14(35 \%)$ and 35 patients (88\%), respectively (Table 1$)$. None of these drugs were discontinued during the study period. The dose of irbesartan was $50 \mathrm{mg}$ per day in 6 patients (15\%), $100 \mathrm{mg}$ per day in 18 patients (45\%) and $200 \mathrm{mg}$ per day in 16 patients $(40 \%)$.

The parameters measured before and after irbesartan treatment are shown in Table 2. There were no significant changes in systolic $(124 \pm 12$ to $122 \pm 12 \mathrm{~mm} \mathrm{Hg}$ ) or diastolic blood pressure $(72 \pm 7$ to $70 \pm 6 \mathrm{~mm} \mathrm{Hg}$ ) or heart rate during irbesartan treatment. The levels of total cholesterol, LDL cholesterol, HDL cholesterol, triglyceride, fasting blood glucose, HbAlc, NT-proBNP, eGFR and hsCRP did not change significantly during irbesartan treatment. However, the levels of serum UA $\left(5.9 \pm 1.6\right.$ to $\left.5.5 \pm 1.6 \mathrm{mg} \mathrm{ml}^{-1}, P=0.028\right)$ and dROMs $(354 \pm 83$ vs. $310 \pm 65$ U.CARR, $P<0.001)$ decreased significantly during the 12 weeks of treatment (Table 2 and Figure 1).

Subanalyses of changes in UA level in patients whose baseline level was greater than the median value of $5.8 \mathrm{mg} \mathrm{dl}^{-1}$ (Upper Group, $n=20$ ) and in patients whose baseline level was $5.8 \mathrm{mg} \mathrm{dl}^{-1}$ (Lower Group, $n=20$ ) were performed. The UA level in the Upper Group decreased significantly during irbesartan treatment (from $7.0 \pm 0.9$ to $\left.6.4 \pm 1.4 \mathrm{mg} \mathrm{dl}^{-1}, P=0.017\right)$. However, the UA level in the Lower Group did not change significantly during irbesartan treatment (from $4.6 \pm 1.0$ to $4.7 \pm 0.9 \mathrm{mg} \mathrm{dl}^{-1}, P=0.641$; Figure 2).

\section{DISCUSSION}

The major findings of our study were reductions in the levels of serum UA and dROMs after irbesartan had been substituted for ARBs other than losartan for 12 weeks. These results suggest that irbesartan is more effective at reducing serum UA and oxidative stress than other ARBs (except losartan).

Several publications have reported the hypouricemic effect of losartan that appears to be mediated by reduction of human urate transporter 1 (URAT1) level, leading to decreased net reabsorption of urate, or UA, in the proximal tubule. ${ }^{24-26}$ The proximal tubule has been identified as the primary location for UA secretion and reabsorption. URAT1 has been shown to have a central role in proximal tubular UA reabsorption. URAT1 is located in the cell membrane on the luminal side of proximal tubular cells, and it reabsorbs UA in exchange for intracellular inorganic anions. Losartan increases UA excretion by inhibiting URAT1-mediated renal tubular UA reabsorption. Early studies in healthy populations showed that the peak uricosuric effects of losartan were observed 2-4h after administration. The time course of this effect suggests that it is losartan itself rather than its active metabolite that blocks URAT1 and causes the reduction in serum UA level. ${ }^{27}$ Recently, Nakamura et al. ${ }^{15}$ demonstrated that irbesartan has a similar or stronger hypouricemic effect to that of losartan that is also due to inhibition of URAT1mediated renal tubular UA reabsorption. Therefore, the results of the present study support this previous report.

Theoretically, the uricosuric effects of irbesartan and losartan could increase urinary UA concentration, potentially causing supersaturation of urine with UA and, in extreme cases, UA nephropathy due to precipitation of UA crystals. However, the risk of developing UA 
Table 2 Post irbesartan treatment parameter changes

\begin{tabular}{|c|c|c|c|}
\hline & Baseline & $\begin{array}{c}12 \text { Weeks after } \\
\text { irbesartan treatment }\end{array}$ & P-value \\
\hline Systolic BP, mm Hg & $124 \pm 12$ & $122 \pm 14$ & 0.618 \\
\hline Diastolic BP, mm Hg & $72 \pm 7$ & $70 \pm 6$ & 0.793 \\
\hline Heart rate, per min & $72 \pm 11$ & $73 \pm 12$ & 0.928 \\
\hline $\mathrm{UA}, \mathrm{mg} \mathrm{dl}-1$ & $5.9 \pm 1.6$ & $5.5 \pm 1.6$ & 0.028 \\
\hline Total cholesterol, $\mathrm{mg} \mathrm{dl}{ }^{-1}$ & $149 \pm 17$ & $152 \pm 17$ & 0.535 \\
\hline LDL cholesterol, $\mathrm{mg} \mathrm{dl}^{-1}$ & $71 \pm 20$ & $72 \pm 21$ & 0.642 \\
\hline HDL cholesterol, mg dl-1 & $46 \pm 12$ & $49 \pm 13$ & 0.379 \\
\hline Triglyceride, $\mathrm{mg} \mathrm{dl}^{-1}$ & $158 \pm 80$ & $149 \pm 79$ & 0.261 \\
\hline Fasting blood glucose, $\mathrm{mg} \mathrm{dl}^{-1}$ & $107 \pm 24$ & $108 \pm 29$ & 0.325 \\
\hline $\mathrm{HbAlc}, \%$ & $6.0 \pm 0.8$ & $6.0 \pm 0.8$ & 0.521 \\
\hline NT-proBNP, pg ml-1 & $244 \pm 259$ & $225 \pm 236$ & 0.386 \\
\hline eGFR, $\mathrm{ml} \mathrm{min}^{-1}$ & $68 \pm 15$ & $68 \pm 14$ & 0.653 \\
\hline hsCRP, $\mathrm{mg} \mathrm{ml}^{-1}$ & $0.12 \pm 0.14$ & $0.09 \pm 0.13$ & 0.292 \\
\hline dROMs, U.CARR & $354 \pm 83$ & $310 \pm 65$ & $<0.001$ \\
\hline
\end{tabular}

Abbreviations: BP, blood pressure; dROM, derivative of reactive oxygen metabolite; eGFR, estimated glomerular filtration rate; HbAlc, glycohemoglobin Alc; HDL, high-density

lipoprotein; hsCRP, high sensitivity C-reactive protein; LDL, low-density lipoprotein; NT-proBNP, $\mathrm{N}$-terminal pro-brain natriuretic peptide; UA, uric acid
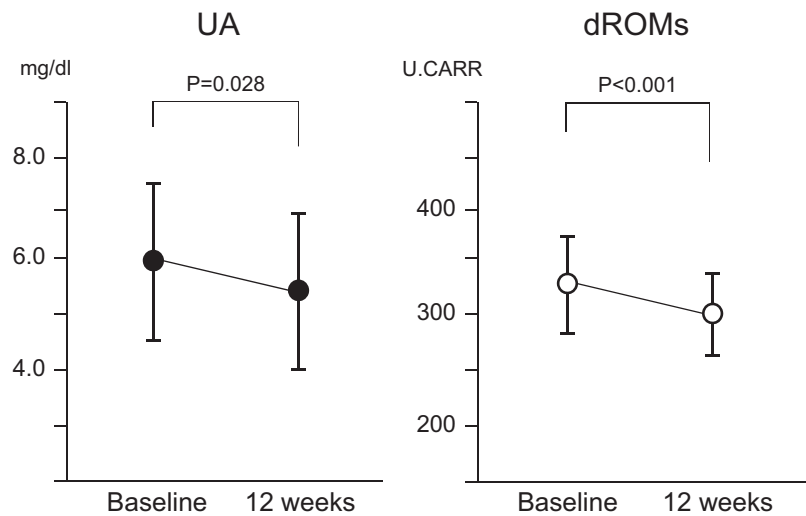

Figure 1 Effects of irbesartan on the levels of serum UA and dROMs. Serum $U A$ and $d R O M s$ decreased significantly during 12 weeks of treatment. UA, uric acid; dROM, reactive oxygen metabolite.

crystals with these ARBs is reduced because of their urinary alkalinizing effects. The increase in urinary $\mathrm{pH}$ caused by these ARBs is attributed to blockade of angiotensin II-induced stimulation of bicarbonate reabsorption. ${ }^{28}$ These findings support the hypothesis that uric acid-lowering therapy slows the progression of chronic kidney disease. Losartan's effect on serum UA level explains $20 \%$ of its renoprotective effect. ${ }^{29}$ The renoprotective effects of irbesartan in hypertensive patients with diabetic nephropathy have been established in large clinical trials. ${ }^{30,31}$ Based on the results of the present study, we hypothesize that the renoprotective effects of irbesartan may also be partially due to a reduction in serum UA level.

We previously found that irbesartan has antioxidant effects, manifested by a reduction of dROMs, in our own I-Mets (irbesartan's metabolic, anti-inflammatory and antioxidant properties) study. ${ }^{17}$ Irbesartan was also shown to lower dROMs in the present study. UA is the final product of purine metabolism in humans. The terminal two reactions in its production, that is, the conversion of hypoxanthine to xanthine and the conversion of the latter to UA, are catalyzed by xanthine oxidoreductase that has two interconvertible forms, xanthine dehydrogenase and xanthine oxidase. The latter uses

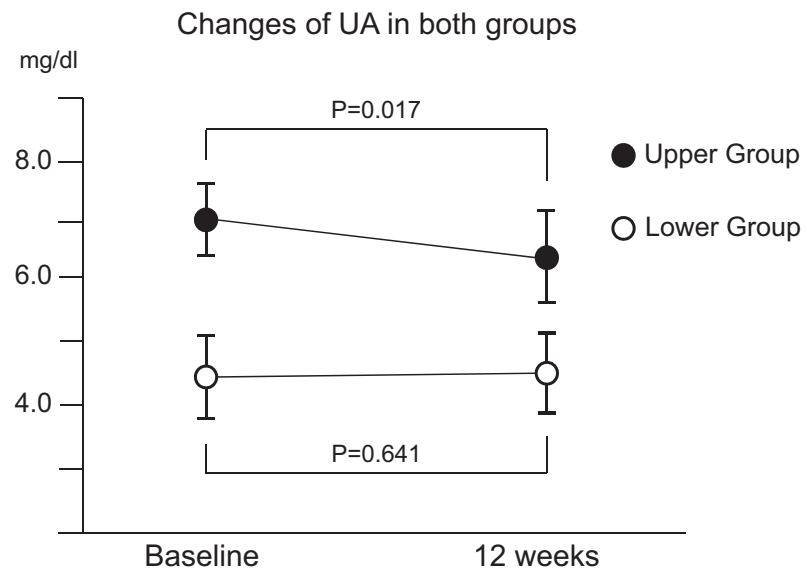

Figure 2 Changes in the UA level in patients whose baseline levels were the median value of $\geq 5.8 \mathrm{mg} \mathrm{dl}^{-1}$ (Upper Group, $n=20$ ) compared with those in whom they were $5.8 \mathrm{mg} \mathrm{dl}^{-1}$ (Lower Group, $n=20$ ). The UA level in the Upper Group decreased significantly during irbesartan treatment (from $7.0 \pm 0.9$ to $6.4 \pm 1.4 \mathrm{mg} \mathrm{dl}^{-1}, P=0.017$ ), whereas that in the Lower Group did not do so $\left(4.6 \pm 1.0\right.$ vs. $\left.4.7 \pm 0.9 \mathrm{mg} \mathrm{dl}^{-1}, P=0.641\right)$. UA, uric acid.

molecular oxygen as an electron acceptor and generates superoxide anions and other reactive oxygen products. ${ }^{32}$ The role of UA in conditions associated with oxidative stress is not clear. Evidence, mainly from epidemiologic studies, suggests that increased serum UA level is a risk factor for cardiovascular diseases in which oxidative stress plays an important pathophysiologic role. Allopurinol, a xanthine oxidoreductase inhibitor that lowers serum UA, also exerts protective effects in situations associated with oxidative stress. ${ }^{32}$ Recently, experimental and clinical evidence that UA plays an important role in vivo as an antioxidant has been accumulating. One of several hypotheses regarding the role of UA in vivo is that, in contrast to the deleterious effect of hyperuricemia in the etiology of gout and lifestyle-related diseases, UA may be beneficial as a powerful antioxidant. ${ }^{33,34}$ Hence, researchers have suggested that hyperuricemia might be a compensatory response to counteract excessive oxidative stress. ${ }^{34}$ In fact, intensive exercise-induced oxidative stress was shown to be reduced by intravenous infusion of UA. ${ }^{34}$ Hyperuricemia may be a response to increased oxidative stress associated with obesity. ${ }^{35}$ Tsukimori et al. ${ }^{36}$ reported that increased serum UA level was closely correlated with plasma hydrogen peroxide level and plasma protein carbonyl level and, thus, served as an indicator of underlying oxidative stress. In the present study, as there was no correlation between the reduction of UA and the reduction of dROMs by irbesartan, the antioxidant effect of irbesartan might be independent of its UA-lowering effect. Chiarelli et al. ${ }^{37}$ demonstrated that irbesartan treatment can substantially increase antioxidant enzyme (catalase and glutathione peroxidase) activity and production and, consequently, the levels of oxidative stress markers (serum malondialdehyde, fluorescent products of lipid peroxidation, monocyte chemoattractant protein-1 and 8-isoprostanes prostaglandin $F_{2 \alpha}$ ). These findings provide a potential explanation for the antioxidant effects of irbesartan in the participants of the present study.

Our previous I-Mets study ${ }^{17}$ demonstrated that irbesartan also improved lipid metabolism and suppressed inflammation. These effects of irbesartan may be partly attributed to an increase in adiponectin levels. ${ }^{38}$ We observed an increase in HDL cholesterol level and a decrease in plasma triglyceride and hsCRP levels associated with a decrease in dROMs. However, in the present study, no significant changes in HDL cholesterol, triglycerides or hsCRP levels 
were observed. This might be because of the small sample size of this study. Nevertheless, the present study showed trends that were essentially similar to the results of the I-Mets study. A study with long-term observation and a larger sample size might show significant changes in these parameters, given that lipid metabolism, inflammation and oxidative stress are related to each other.

In the present study, fasting blood glucose, HbAlc, NT-proBNP and eGFR levels did not change significantly. However, several previous reports have demonstrated that reductions in serum UA level and oxidative stress help improve glucose metabolism, heart failure and renal function; therefore, similar effects of irbesartan might be demonstrable if patients are stratified according to baseline UA level.

Regarding cardiovascular end points, a subanalysis of the Losartan Intervention for Endpoint Reduction in Hypertension (LIFE) study showed that the superior effects of losartan can be partly explained by its effect on serum UA level. ${ }^{39}$ However, coronary artery disease and heart failure guidelines do not include recommendations for the control of serum UA level, ${ }^{40}$ because UA has variable associations with different cardiovascular disease states. ${ }^{41}$ As serum UA level at baseline and gender both influence the effects of UA-lowering therapy, ${ }^{41}$ when evaluating treatment efficacy, it may be important to stratify patients using several parameters. As the UA-lowering effect of irbesartan in the present study was only observed in patients whose baseline UA level exceeded the median value, the threshold value and mechanism of this apparent effect warrant further study. In addition, a limitation of this study is that it was not a randomized controlled trial. Therefore, prospective, randomized, controlled trials evaluating hard end points are needed to confirm that lowering UA level improves the long-term outcomes of cardiovascular diseases. Finally, future basic research should elucidate the interactions of the roles of UA, oxidative stress and inflammation in vivo.

\section{CONCLUSION}

In high-risk hypertensive patients, irbesartan may exhibit beneficial effects on hyperuricemia in addition to its effects on oxidative stress.

\section{CONFLICT OF INTEREST}

The authors declare no conflict of interest.

1 Messerli FH, Frohlich ED, Dreslinski GR, Suarez DH, Aristimuno GG. Serum uric acid in essential hypertension: an indicator of renal vascular involvement. Ann Intern Med 1980; 93: 817-821.

2 Lin KC, Lin HY, Chou P. The interaction between uric acid level and other risk factors on the development of gout among asymptomatic hyperuricemic men in a prospective study. J Rheumatol 2000; 27: 1501-1505.

3 Fang J, Alderman $\mathrm{MH}$. Serum uric acid and cardiovascular mortality the NHANES I epidemiologic follow-up study, 1971-1992. National Health and Nutrition Examination Survey. JAMA 2000; 283: 2404-2410.

4 Sundstrom J, Sullivan L, D'Agostino RB. Relations of serum uric acid to longitudina blood pressure tracking and hypertension incidence. Hypertension 2005; 45: 28-33.

5 Feig DI, Kang DH, Johnson R. Uric acid and cardiovascular risk. N Engl J Med 2008, 359: 1811-1821.

6 Conen D, Wietlisbach V, Bovet P. Prevalence of hyperuricemia and relation of serum uric acid with cardiovascular risk factors in a developing country. BMC Public Health 2004: 4: 9 .

7 Bhole V, Choi JW, Kim SW, de Vera M, Choi H. Serum uric acid levels and the risk of type 2 diabetes: a prospective study. Am J Med 2010; 123: 957-961.

8 Hovind P, Rossing P, Tarnow L, Johnson RJ, Parving HH. Serum uric acid as a predictor for development of diabetic nephropathy in type 1 diabetes: an inception cohort study. Diabetes 2009; 8: 1668-1671.

9 Bellomo G, Venanzi S, Verdura C, Saronio P, Esposito A, Timio M. Association of uric acid with change in kidney function in healthy normotensive individuals. Am J Kidney Dis 2010; 56: 264-272.
10 Wen CP, David Cheng TY, Chan HT. Is high serum uric acid a risk marker or a target fo treatment? Examination of its independent effect in a large cohort with low cardiovascular risk. Am J Kidney Dis 2010; 56: 273-288.

11 Fauvel JP, Velon S, Berra N, Pozet N, Madonna O, Zech P. Effects of losartan on renal function in patients with essential hypertension. J Cardiovasc Pharmacol 1996; 28 259-263.

12 Kim EJ, Song WH, Lee JU, Shin MS, Lee S, Kim BO. Efficacy of losartan and carvedilol on central hemodynamics in hypertensives: a prospective, randomized, open, blinded end point, multicenter study. Hypertens Res 2014; 37: 50-56.

13 Manolis AJ, Grossman E, Jelakovic B, Jacovides A, Bernhardi DC, Cabrera WJ. Effects of losartan and candesartan monotherapy and losartan/hydrochlorothiazide combination therapy in patients with mild to moderate hypertension: Losartan Trial Investigators. Clin Ther 2000; 22: 1186-1203.

14 Elliott WJ, Calhoun DA, DeLucca PT, Gazdick LP, Kerns DE, Zeldin RK. Losartan versus valsartan in the treatment of patients with mild to moderate essential hypertension: data from a multicenter, randomized, double-blind, 12-week trial. Clin Ther 2001; 23 1166-1179.

15 Nakamura M, Anzai N, Jutabha P, Sato H, Sakurai H, Ichida K. Concentrationdependent inhibitory effect of irbesartan on renal uric acid transporters. J Pharmacol Sci 2010: 114: 115-118.

16 Wurzner G, Gerster JC, Chiolero A, Maillard M, Fallab-Stubi CL, Brunner HR Comparative effects of losartan and irbesartan on serum uric acid in hypertensive patients with hyperuricaemia and gout. J Hypertens 2001; 19: 1855-1860.

17 Taguchi I, Toyoda S, Takano K, Arikawa T, Kikuchi M, Ogawa M, Abe S, Node K, Inoue T. Irbesartan, an angiotensin receptor blocker, exhibits metabolic, anti-inflammatory and anti-oxidative effects in patients with high-risk hypertension. Hypertens Res 2013, 26: 608-613

18 Node K, Inoue T, Boyko V. Long-term effects of peroxisome proliferator-activated receptor ligand bezafibrate on $\mathrm{N}$-terminal pro-B type natriuretic peptide in patients with advanced functional capacity impairment. Cardiovasc Diabetol 2009; 8: 5.

19 Matsuo K, Inoue T, Node K. Estimated glomerular filtration rate as a predictor of secondary outcomes in Japanese patients with coronary artery disease. J Cardiol 2009; 53: 232-239.

20 Rifai N, Tracy RP, Ridker PM. Clinical efficacy of an automated high-sensitivity C-reactive protein assay. Clin Chem 1999; 45: 2136-2141.

21 Cearone MR, Belcalo G, Carratelli M. A simple test to monitor oxidative stress. Int Angiol 1999; 18: 127-130.

22 Cornelli U, Terranova R, Luca S, Cornelli S, Alberti A. Bioavailability and antioxidant activity of some food supplements in men and women using the D-Roms test as a marker of oxidative stress. J Nutr 2001; 131: 3208-3211.

23 Cavalleri A, Colombo C, Venturelli E. Evaluation of reactive oxygen metabolites in frozen serum samples. Effect of storage and repeated thawing. Int J Biol Markers 2004; 19: 250-253.

24 Kehrer JP. The Haber-Weiss reaction and mechanisms of toxicity. Toxicology 2000 149: 43-55.

25 Burnier M, Brunner HR. Renal effects of angiotensin II receptor blockade and angiotensin-converting enzyme inhibition in healthy subjects. Exp Nephrol 1996; 4 $41-46$

26 Nindita Y, Hamada T, Bahrudin U. Effect of losartan and benzbromarone on the level of human urate transporter 1 mRNA. Arzneimittelforschung 2010; 60: 186-188.

27 Hamada T, Ichida K, Hosoyamada M. Uricosuric action of losartan via the inhibition of urate transporter 1 (URAT 1) in hypertensive patients. Am J Hypertens 2008; 21 $1157-1162$.

28 Miao $Y$, Ottenbros SA, Laverman GD. Effect of a reduction in uric acid on renal outcomes during losartan treatment: a post-hoc analysis of the reduction of endpoints in non-insulin-dependent diabetes mellitus with the Angiotensin II Antagonis Losartan Trial. J Hypertens 2011; 58: 2-7.

29 Parving $\mathrm{HH}$, Lehnert $\mathrm{H}$, Brochner-Mortensen J, Gomis R, Andersen S, Arner P. The effect of irbesartan on the development of diabetic nephropathy in patients with type 2 diabetes. N Engl J Med 2001; 345: 870-878.

30 Lewis EJ, Hunsicker LG, Clarke WR. Collaborative Study Group. Renoprotective effect of the angiotensin-receptor antagonist irbesartan in patients with nephropathy due to type 2 diabetes. N Engl J Med 2001; 345: 851-860.

31 Glantzounis GK, Tsimoyiannis EC, Kappas AM, Galaris DA. Uric acid and oxidative stress. Curr Pharm Design 2005; 11: 4145-4151.

32 Nieto FJ, Iribarren C, Gross MD, Comstock GW, Gutler RG. Uric acid and serum antioxidant capacity: a reaction to atherosclerosis? Atherosclerosis 2000; 148: $131-139$.

33 Nyyssonen K, Porkkala-Sarataho E, Kaikkonen J. Ascorbate and urate are the strongest determinants of plasma antioxidative capacity and serum lipid resistance to oxidation in Finnish men. Atherosclerosis 1997; 130: 223-233.

34 Waring WS, Convery A, Mishra V, Shenkin A, Webb DJ, Maxwell SRJ. Uric acid reduces exercise-induced oxidative stress in healthy adults. Clin Sci 2003; 105: 425-430.

35 Evans JL, Maddux BA, Goldfine ID. The molecular basis for oxidative stress-induced insulin resistance. Antioxid Redox Signal 2005; 7: 1040-1052.

36 Tsukimori K, Yoshitomi T, Morokuma S, Fukushima K, Wake N. Serum uric acid levels correlate with plasma hydrogen peroxide and protein carbonyl levels in preeclampsia. Am J Hypertens 2008; 21: 1343-1346.

37 Chiarelli F, Marzio D, Santilli F, Mohn A, Blasetti A, Cipollone F, Mezzetti A, Verrotti A. Effects of irbesartan on intracellular antioxidant enzyme expression and activity in adolescents and young adults with early diabetic angiopathy. Diabetes Care 2005; 28 : 1690-1697. 
38 Takagi H, Mizuno Y, Yamamoto H, Goto S, Umemoto T. All-Literature Investigation of Cardiovascular Evidence Group. Effects of telmisartan therapy on interleukin-6 and tumor necrosis factor-alpha levels: a meta-analysis of randomized controlled trials. Hypertens Res 2013; 36: 368-373.

39 Hoieggen A, Alderman MH, Kjeldsen SE. The impact of serum uric acid on cardiovascular outcomes in the LIFE Study. Kidney Int 2004; 65: 1041-1049.

40 Smith SC, Benjamin EJ, Bonow RO, Braun LT, Creager MA, Franklin BA, Gibbons RJ, Grundy SM, Hiratzka LF, Jones DW, Lloyd-Jones DM, Minissian M, Mosca L,
Peterson ED, Sacco RL, Spertus J, Stein JH, Taubert KA. AHA/ACCF Secondary Prevention and Risk Reduction Therapy for Patients With Coronary and Other Atherosclerotic Vascular Disease: 2011 Update a guideline from the American Heart Association and American College of Cardiology Foundation. Circulation 2011; 124: 2458-2473.

41 Ishizaka N, Ishizaka Y, Toda E, Nagai R, Yamakado M. Association between serum uric acid, metabolic syndrome, and carotid atherosclerosis in Japanese individuals. Arterioscler Thromb Vasc Biol 2005; 25: 1038-1044. 